Original Research Paper

\title{
Mapping Gamification Mechanisms to User Experience Factors for Designing User Interfaces
}

\author{
Nahed Alsaleh and Reem Alnanih \\ Department of Computer Science, Faculty of Computing and Information Technology, \\ King Abdulaziz University, Jeddah, Saudi Arabia
}

Article history

Received: 28-01-2019

Revised: 11-03-2019

Accepted: 29-05-2019

Corresponding Author:

Reem Alnanih

Department of Computer

Science, King Abdulaziz

University, Jeddah, Saudi

Arabia

Email: ralnanih@kau.edu.sa

\begin{abstract}
Healthy living applications have been proposed as an ideal tool for behavior change. The use of gamification in healthcare interventions is gaining popularity, but there is still a need to clarify how to employ the benefit of this technology for managing children's behavior. This paper proposes a new approach for mapping Gamification Mechanism (GM) to User Behavior Techniques (UBTs) considering User Experience (UX) factors. The reason for this mapping is to provide a list of recommendations for the gamification designers to include new design features in designing and developing the user interface for mobile games to sustain user engagement and to keep using the game for the benefit of changing behavior. The proposed design aims to provide a solution for both the provider (designer) and consumer (user) of the healthcare application. The benefits of the proposed approach help to increase the usability, awareness and attention of the user through engaging in the gamification.
\end{abstract}

Keywords: Gamification, User Experience, User Behavior, Transtheoretical Model, Interactive Design

\section{Introduction}

Healthy living applications have been proposed as an ideal tool for behavior change. Smartphones enable reinforcement throughout the day and provide context specific advice (Dennison et al., 2013). This is a great opportunity for developers of health applications to encourage users to make lifestyle changes, such as reducing stress levels or increasing physical activity to achieve health and wellness goals.

The idea of changing human health behavior is a vital one. From our perspective, this change requires three factors: First, a technique is needed to develop behaviors that help prevent disease and reduce mortality. Second, a method of technology is required in terms of "gamification" to apply the technique. Third, an understanding of the User Experience (UX) factors that affect the changing behavior is needed. A behavior change technology is a systematic procedure that includes an active component of a behavior change intervention. The characteristic components of a behavior changing technique are observability, replicability and irreducibility. These components are designed to change or redirect causal processes that regulate behavior (Michie et al., 2013).

A behavior change technology is called an "active ingredient"; examples are feedback, self-monitoring and reinforcement (Michie et al., 2013; Sims, 2015). A definition of behavior aligned across many disciplines is a person doing anything in response to internal or external events. Actions may be directly or indirectly measurable. Behaviors are physical events that occur in the body and are controlled by the brain (Savoia et al., 2013). The most important benefits of using tablet applications in the health field are recognizing the increasing risks of disease and linking this information to the idea of gamification. These applications can help people change their unhealthy lifestyles. They have also encouraged developers to design more health applications. One of the most difficult challenges for health is using game mechanism and principles, such as competition, to engage and educate patient (McGonigal, 2011a).

\section{Contribution}

Our contribution in this paper is to propose an approach for mapping Gamification Mechanism (GM) to User Behavior Techniques (UBTs) considering UX factors. The reason for this mapping is to provide a list of recommendations for the gamification designers to include new design features in designing and developing the user interface for mobile games to sustain user engagement to keep using the game for the benefit of changing behavior. Another reason is applying the gaming elements to a real-world activity, such as in the healthcare context, in a seamless and ubiquitous way. 


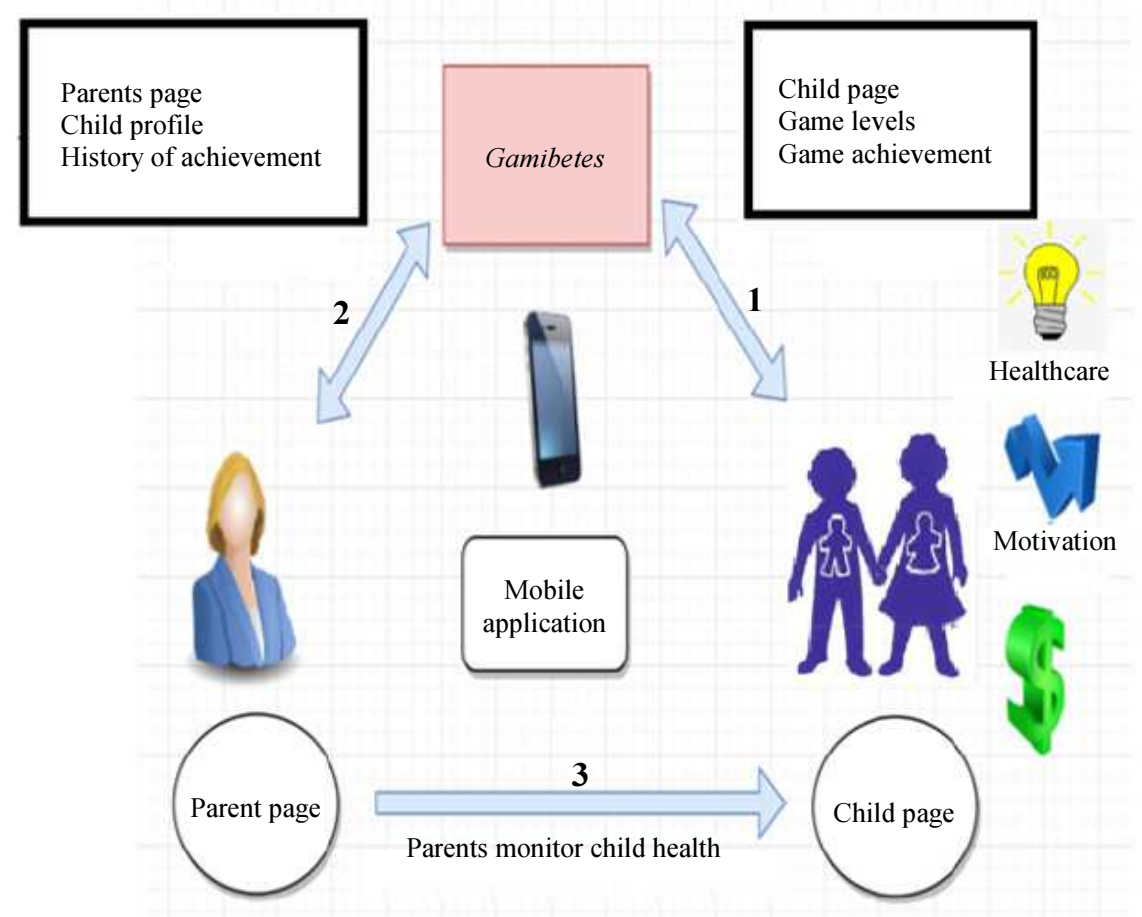

Fig. 1: Structure of the gamification approach

\section{The Proposed Approach}

We name the User Interface (UI) design for gamification on a tablet UI gamification (UIG). The designer of a UIG integrates UBT and UX into the interface behavior, both at the design and usage levels. The proposed approach will advance the gamification outcome with the utility of a UX that adapts to user behavior. Figure 1 illustrates the structure of the propose approach by presenting an example for a scenario of a patient who is a "child" suffering from "diabetes" using "gamification," as follows:

1. The child with diabetes plays and interacts with the application through his or her view in a mobile or iPad game; consequently, the child moves between the levels of the game and achieves the goal

2. Parents access the application through their view

3. Parents can monitor their child through the game and observe the child's achievements

\section{Motivation of the Work}

The use of mobile computing applications has become more widespread for ease of use and providing multiple services for users in different ways in the areas of education, entertainment, health and so on.

The impact of applying gamification in changing behaviour of children with diabetes should not be overlooked (Silva and Analide, 2015). Continuous development and improvement is desirable and have great implication on the whole system towards a positive result (Silva and Analide, 2015). The categorization of these conditions improve the healthy life. As the technological sophistication of mobile devices has grown, the UIG for mobile devices are becoming increasingly complex. Consequently, the UIG design must be both useful and usable and it is necessary to consider this technology's role in changing user behavior. Smartphone usage has grown rapidly in recent years in both developed and developing countries. There were over 2 billion smartphone users in the world in 2016 and in 2018, it is estimated that one-third of the world's population is using smartphones (Edwards et al., 2016). Computer and video games form a vast industry. According to researcher (McGonigal, 2011b), there are currently more than half a billion people playing computer and video games worldwide for at least an hour a day, 183 millions of which reside in the United States alone. Furthermore, 5 million players in the United States spend more than $40 \mathrm{~h}$ a week on gaming, which is equivalent to a fulltime job.

Gamification is increasingly supported in education. In New York City, the Quest2Learn school, is trying to gamify an entire school system (Cohen, 2011). In the Quest2Learn school, lectures like science, math and social studies take place in virtual game worlds, which 
have bad characters like monsters to fight (Cohen, 2011). Mobile game technology is an integral part of the modern healthcare environment. Mobile game applications have the potential to deal with massive global healthcare market. The mobile game application serves as the bridge across different types of user's behaviors who use the applications for different purposes. Health applications are available worldwide and have spread significantly. About 100,000 health applications are available globally for smartphones (Donker et al., 2013). These services have diversified in the health field and have helped to address different needs, such as diet, smoking cessation, follow up for diseases, blood pressure and daily exercise. For children, games can be used to encourage them to recognize what benefits them. This has encouraged developers to think about gamification and design more health applications for this category of users. Therefore, developers must pay attention to health applications that not only track users' health but also motivate them to correct unhealthy behaviors and help improve their everyday life. The applications and gamification are effective in monitoring care for a wide range of chronic and persistent diseases, such as diabetes, that children may suffer from, from mild to severe and common to rare conditions (Sims, 2015).

A major reason for considering gamification as a tool in changing the behavior of children in health care is the critical need to improve the care of the large and increasing number of children with multiple chronic conditions without increasing healthcare costs significantly (Michie et al., 2013). To have an effect, gamification developers must be aware of guidelines and take measures to ensure that their mobile GUI or health application will be accepted by caregivers, patients, healthcare professionals, parents and other end users. Before designing an interface or developing a game, designers and developers need to determine what functionality is necessary to engage children to keep using it. To address motivation, they can capture relevant aspects of UX factors and UBT, such as observation (Michie et al., 2013).

\section{Related Work}

The Information and Communication Technologies (ICTs) are now used in health care, which has had a major impact on the health industry, especially in chronic diseases like heart disease, stroke, chronic respiratory disease, diabetes and obesity (Lister et al., 2014). Mobile health technology is not limited to applications; Free et al. (2013) found that text messaging is used to help patients adhere to medication for some health conditions. Payne et al. (2015) systematically reviewed and presented the literature on application use in behavior change, application benefits in changing health behavior and behavioral change features. Donker et al. (2013) achieved systematically the effectiveness of mental health applications for mobile devices. They concluded that applications have the potential to provide a benefit for poor mental health.

Researchers have developed applications to help people change their poor health behaviors by monitoring them. These applications can enhance self-monitoring by providing information and testing healthy nutrition in real time. There are many proposed projects that help individuals with chronic diseases and healthy people to monitor their health behavior. Connelly et al. (2006) developed an application of Dietary Intake Monitoring Application (DIMA) for dialysis patients to monitor their food consumption by providing feedback in real time. Sethares and Elliott (2004) considered factors that influence the potential success of applications to support health promotion. They argue that it is important to focus on youth and elicit their opinions on applications aimed at changing health-related behavior.

Gamification applied in many innovative approaches to educate and encourage the user to follow the right behave. Briones et al. (2018) applied the gamification concept in the recycling process in a way that rewards offered to users according to the amount of waste deposited in the container. In the same field, another framework proposed that integrates gamification methodologies with multi-agent technology to demonstrate the benefits of the developed system. This framework improved the engagement of the participants in the recycling process by rewarded for the amount they recycle (González-Briones et al., 2018).

Brondino et al. (2014) presented a research work in the education field in the context of children in primary school. Their goal was to encourage the children to create paper game design ideas and prototypes based on gamification principles to track their emotions experienced during game design at school time (Brondino et al., 2014). The authors measured the children emotions in different social context before and after the game design activity (Brondino et al., 2014). The results show that positive emotions play an essential role in improving the social relations of children, while negative emotions associated with a significant deterioration in social relations in the context of out-ofschool recreation (Brondino et al., 2014).

\section{Gamification in Health Care}

Gamification is a new technology that incorporates elements of game play in nongame situations (Lee et al., 2017). It is used to engage different groups of people, such as customers, students, children and others in the accomplishment of quotidian tasks using rewards and 
other motivators (Lee et al., 2017). Gamification was created by the computer gaming industry and uses game mechanism and thinking in a context other than games to attract users, guide behavior and solve problems (Connelly et al., 2006). Gamification is a comprehensive term comprising the use of "games" elements to motivate and engage people in contexts other than games (Cafazzo et al., 2012). A game is defined as a technique in which actors are involved in abstract challenges, with preliminary rules, interactivity and feedback; the game leads to measurable results and often triggers an emotional reaction (Brull and Finlayson, 2016). There is a similarity between the rubrics for components of gamification and that for game elements due to the adoption of gamification from the field of video games. Video games for health are an effective and exciting way of increasing health understanding and knowledge, conveying convincing messages, changing health behaviors and influencing health outcomes (Hamari et al., 2014). Given the relative ease of creating mobile apps compared with computer apps and their considerably lower price, mobile apps represent a growing industry that produces more and more applications each year. The most popular Apple App Store category is gaming, with about 25 percent of available apps belonging to this category (Bruder, 2015).

The use of gamification in mobile app technology is a common strategy in both commercial culture and the field of academia as a means of promoting healthy behaviors (Deterding et al., 2011; Lister et al., 2014). Gamification uses rewards and game-like incentives, combined with desired behaviors, to help increase motivation and maintain individuals' habits over time (Deterding et al., 2011; King et al., 2013). The use of this tactic in the field of health has grown despite their having been little to no in-depth investigation of its effectiveness and appropriate functionality (Ferguson, 2012; Ferrara, 2013). Lister et al. (2014) focused on analyzing the gamification of health and fitness apps as a potential component influencing consumer health behavior. In a Korean study, the authors examined how gamification affects the user's intent to use Mobile health care (M-Health) applications and how the gamification effect works differently depending on health status, age and sex. The results showed that gamification is effective in augmenting the user's intent to use mental health applications, especially in younger age groups (Lee et al., 2017). These findings suggest that M-Health with a gamification factor would encourage healthy people and gamification people to maintain their health status. Cafazzo et al. (2012) designed an application for diabetes M-Health using gamification incentives for manipulation and the application showed an improvement in the frequency of blood glucose control in adolescents with type I diabetes. In
Edwards et al. (2016) the researches systematically reviewed health applications that contain elements of decomposition games their embedded behavior change techniques. The results show that the use of gamification in health and fitness applications is common, as evidenced by the number of applications available in the Apple store (Edwards et al., 2016).

Adapting gamification techniques plays an important role in the workplace. Gamification in the work environment is extremely different from that related to the consumer, online or internet community. Therefore, we must fully understand and recognize the advantages and disadvantages of the gamification process and we must especially understand that it should not be seen as a solution proper, but rather, as a tool that has positive and negative effects on the workforce (Prakash and Rao, 2015). Most of the research described above has neglected the advantages of designing the gamification based on UX factors. In this paper, we focus on the approach of designing gamification in health care based on the UX and how this aligns with the benefit of the UBT. One of the ways of achieving this is to map the GM to UX in healthcare domain.

\section{Mapping User Behavior and User Experience Factors ONTO Gamification}

In this section, we propose our approach for mapping user behavior and UX factors to the gamification technique. We illustrate our approach with simple but nontrivial example of children with diabetes playing a game with the aim of changing their behavior toward eating healthy food. The design goal is to develop a GUI that is mapp to UX and the user behavior techniques. The following subsections clarify the three dimensions of our model, which are GM, user behavior, UX factors.

\section{Gamification Mechanism}

In this section, we shed light on the game mechanism that should be used in designing and developing gamification. The mechanism of the game contain challenges, points, manipulators, badges, rewards, leaderboards and levels (Hamari et al., 2014). Using game mechanism and various types of game strategies allows learners to problem solve in a fun and engaging way (Bruder, 2015). The game mechanism need to be united with realistic goals, rules and feedback (McGonigal, 2011a). The four types of mechanism most commonly used in gamification processes are applied in our approach and they are defined as follows (McGonigal, 2011a):

- Points: There are several ways to use points so that learning is more engaging. These points give immediate feedback so that they can be displayed to 
others and see how good the player is (Werbach and Hunter, 2012). These points illustrate progress easily and display data to the educator, who can then see the learner's understanding of the material

- Badges: The badge is shown as a visual indication that the player has attained something. Numerous exercise programs give player a badge when they take 10,000 steps. Badges are an adaptable process that can be applied in any type of activity and showcase achievements through social media

- Leveling up: Levels help members learn how to advance in content (Bruder, 2015). Teachers use the levelling to help learners to progress by completing tasks, scoring points, or collecting objects. The leveling up process is easy to use and can be applied when the teacher is trying to distinguish specific groups from one another

- Leaderboards: Leaderboards show how many people play a game and how the player is doing relative to other players. Many leaderboards only show the most important players. Leaderboards offer a little bit of competition and can be a fun way to motivate players to continue learning content (i.e., becoming the highest leader on the leaderboard)

\section{User Behavior}

In this section, we study the different principles that play a significant role in changing behavior. These principles are based on the Transtheoretical Model (TTM) (Brick et al., 2016; Prochaska, 2013). TTM specify the process of activities that people use to progress through separate stages (Riekert, 2013). Many research adapts the TTM in health behavior change, for example, smokers and self-changers, alcohol, substance abuse, obesity and medication compliance (Prochaska, 2013). TTM focuses on the individual's decision-making process and it is a model for deliberate change. The theoretical framework of the TTM according to changing behavior pass through many stages. Each stage aims to work on the part of changing behavior. By achieving all the steps, the action of the user has significant improvement (Brick et al., 2016).
The TTM works on the assumption that people change behaviors slowly and non-decisively. In this viewpoint, changes in behavior, related to habitual behavior, occur continuously through a cyclical process (Brick et al., 2016). In our proposed approach, the interaction is based on changing the child's health behavior through encouraging the child to interact with a gamification that promotes the desired health outcome. The TTM posits that individuals' behavior moves through six stages of change, as follows (Brick et al., 2016):

1. Precontemplation: In this phase, individuals are unaware of the problem, so they do not intend to take any action for future change

2. Contemplation: In this phase, individuals realize that there is a problem with their behavior and they intend to start changing their health behavior in the future. Even with this recognition, so far, the people feel the contradiction toward changing their behavior

3. Preparation: In this phase, individuals are ready to change their health behavior in the next few days. They begin by taking small steps and they feel that changing their behavior will lead to a healthier life

4. Action: In this phase, individuals have recently changed their behavior and believe in continuing this change. The change occurs in several ways and it can involve the individuals modifying their behavior or acquiring new health behaviors

5. Maintenance: In this phase, individuals have changed their behavior for a period of time and intend to sustain the change in the future. This intention prevents them from relapsing to the previous phases

6. Termination: In this phase, people do not want to return to unhealthy behaviors and they are sure they will not regret this decision. This step is rarely reached and some people prefer to stay in the maintenance phase, so this phase is not always present in health-promotion programs

Table 1: Properties of the TTM of change

\begin{tabular}{|c|c|c|c|}
\hline TTM Stages & GM & $\begin{array}{l}\text { Extract TTM } \\
\text { Properties }\end{array}$ & Justification \\
\hline Contemplation & Points & Feedback Progress & $\begin{array}{l}\text { Contemplation gives the player feedback and reflect the player progress } \\
\text { through collecting the points in the game. }\end{array}$ \\
\hline Preparation & Badges & $\begin{array}{l}\text { Achievement } \\
\text { Flexible Process }\end{array}$ & $\begin{array}{l}\text { Preparation outlines the player's achievement by obtaining the badges in } \\
\text { the game, which reflect the features of flexibility of applying in different } \\
\text { Context in the game. }\end{array}$ \\
\hline Action & Leveling up & Advanced & $\begin{array}{l}\text { Action demonstrates the advance of the player in the progress of the } \\
\text { steps by passing to the next level. }\end{array}$ \\
\hline Maintenance & $\begin{array}{l}\text { Leader- } \\
\text { boards }\end{array}$ & $\begin{array}{l}\text { Completion } \\
\text { Fun to apply }\end{array}$ & $\begin{array}{l}\text { Maintenance motivates the player to continue learning the good behavior } \\
\text { in the game in a fun way by being listed on the leaderboards in the game. }\end{array}$ \\
\hline
\end{tabular}


Table 1 justifies our mapping approach between the (GM) and user behavior in terms of (TTM) stages in the context of our mentioned example. We should point out that the first and last steps of TTM are excluded in the mapping, reflecting the beginning and ending of the cycle.

\section{User Experience Factors}

In this subsection, we present the UX and how it is critical for a product's success or failure in the design. UX is all that relates to a user's behavior, attitude and feelings about using a particular product, system, or service. In addition, "UX is the tangible design of a strategy that brings us to a solution" (Fanfarelli et al., 2018). Often, people confuse UX with ease of use; although the UX begins with ease of use, it expands to accommodate more usability. Considering all aspects of UX is vital in delivering successful products to the market. For great designers, looking deeper into how people think and behave is important.

Fanfarelli et al. (2018) seven factors describe the UX. To consider the benefits of these factors in our mapping approach, we justify each one and clarify how it is important to our mapping, as well as how it is applied in the gamification of our example. The factors are as follows:

1- Useful: This gamification factor is useful for changing the behavior of children with disease, for example, diabetes. It can be considered "useful" because it brings educational benefits, as well as fun and aesthetic appeal. This gamification factor combines the usefulness of tracking by parents with the fun and play for the child. Through this experience of pleasure, the gamification can teach the child about the damage of eating sweets, as well as defining diabetes more clearly

2- Usable: The gamification is easy to use, with effective access to Android or iPhone tablets; it can be obtained faster and easier than other apps, enabling users to achieve their goals

3- Easy to Find: According to this factor, the designed gamification should be easily found; in terms of digital and information products, the content in them must be easy to find, because time is considered valuable due to the main factor of a "limited lifespan" (Fanfarelli et al., 2018). The application on the tablet is easy to obtain, as there is more than one mobile phone in each home, in addition to the presence of iPads for children

4- Credible: The product must be reliable because it is easy to look for alternatives in every area. Users cannot be fooled in the 21 st century and they will leave quickly if designers do not give them a reason to stay. Credibility depends on the user's ability to trust the provided product; that is, the user must trust not only that the product does the work it is supposed to do, but also that it will continue to do so for a reasonable period (Fanfarelli et al., 2018). The user must have a good impression of gamification and its trustworthiness

5- Desirable: The desire for the design is conveyed through brand, image, identity, aesthetics and emotional design. The more desirable the product, the more likely its user is to boast about its use and create a desire for the product in other users. The gamification must be the most desirable in terms of design, colors, images and other attributes. For children, the design must focus on being colorful

6- Accessible: Accessibility is providing an experience for users to access a full range of capabilities (Fanfarelli et al., 2018). When designing accessibility, it is often necessary to create products that are easy for everyone to use, not just people with disabilities

7- Valuable: The gamification must provide value for the work it creates and the user who purchases or uses it. Without value, it is likely that any initial success of the product will eventually vanish as the realities of the natural economy begin to undermine it (Fanfarelli et al., 2018)

\section{Justification}

The following points provide the justification for the mapping between GM and the UX factors:

- Mapping points to the desirable, valuable and credible attributes:

- When using points in several ways in gaming, learning becomes more engaging and gaming becomes desirable

- These points determine the quality of the player and are linked to the valuable factor in the UX

- When the administrators of the game observe the extent of the learner's understanding of the game, the game achieves the factor of being credible in the UX

- Mapping badges to the useful, usable and easy to find attributes:

- The badges are a sign that the player has achieved something, serving the useful factor in the UX

- Badges are flexible processes that can be implemented and achieve the usable factor

- Since badges can provide a social component that can be used on social media platforms, they serve the easy to find factor in the UX 
- Mapping leveling up to the useful, usable, valuable and accessible attributes:

- Using the leveling up feature helps participants learn how to progress in the content of the game and this serves useful factor in the UX

- Leveling up can also be easy to use and this serves the usable factor in the UX. The administrator can also distinguish between groups and this makes the product valuable

- Administrators use leveling up to require learners to progress by completing tasks and this serves the accessible factor in the UX
- Mapping leaderboards to the desirable and useful attributes:

- A leaderboard is an incentive for competition in a fun way and this serves the desirable factor in the UX

- The leaderboard helps players to learn the content and this serves the useful factor in the UX

Figure 2 presents the user behavior stages (TTM) as a foundation for mapping GM and the UX factors. The UX factors need to be considered while designing the game UI.

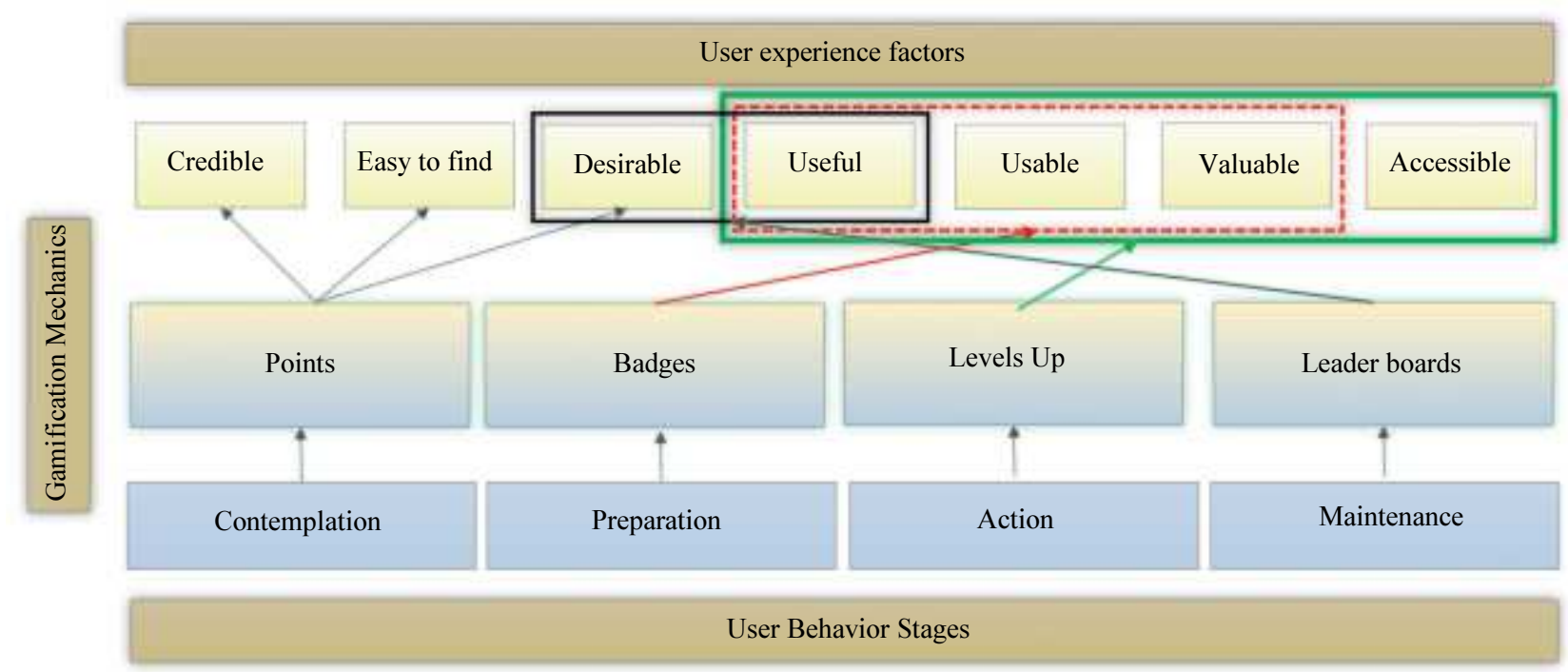

Fig. 2: Mapping gamification mechanisms to UX factors

Table 2: Recommendation list for designing and developing a UIG based on the mapping approach

\begin{tabular}{|c|c|c|c|}
\hline TTM stages & GM & UX factors & Recommendation list \\
\hline $\begin{array}{l}\text { Contemplation } \\
\text { (feedback and } \\
\text { progress) }\end{array}$ & Points & $\begin{array}{l}\text { - Credible } \\
\text { - Desirable } \\
\text { - Easy to find }\end{array}$ & $\begin{array}{l}\text { 1. The designer can see the player's understanding of the game through the } \\
\text { points so that the progress is easy and has credibility. } \\
2 \text {. The designer can change the behavior by determining the quality of the } \\
\text { player using points. } \\
\text { 3. A player can more engaged player because the use of points makes } \\
\text { learning more attractive. }\end{array}$ \\
\hline $\begin{array}{l}\text { Preparation } \\
\text { (achievement } \\
\text { and flexible) }\end{array}$ & Badges & $\begin{array}{l}\text { - Valuable } \\
\text { - Useful } \\
\text { - Usable }\end{array}$ & $\begin{array}{l}\text { 4. The designer can easily turn off or disable settings because the badges } \\
\text { are a flexible process that can be executed in any application. } \\
5 \text {. The designer can provide accurate and reliable information using badges } \\
\text { so that they can be displayed clearly on media platforms. }\end{array}$ \\
\hline $\begin{array}{l}\text { Action } \\
\text { (advanced) }\end{array}$ & $\begin{array}{l}\text { Leveling } \\
\text { Up }\end{array}$ & $\begin{array}{l}\text { - Valuable } \\
\text { - Useful } \\
\text { - Usable } \\
\text { - Accessible }\end{array}$ & $\begin{array}{l}\text { 6. The designer can create positive alerts by using levels up so that the } \\
\text { groups are distinguished. } \\
\text { 7. The designer can achieve sustainability over long periods by using levels } \\
\text { so that the player wants to complete tasks, score points and learn how to } \\
\text { progress. } \\
\text { 8. The player can require low effort through levels up using levelling to be } \\
\text { easy to use. }\end{array}$ \\
\hline $\begin{array}{l}\text { Maintenance } \\
\text { (completion } \\
\text { and fun to apply) }\end{array}$ & $\begin{array}{l}\text { Leader } \\
\text { boards }\end{array}$ & $\begin{array}{l}\text { - Desirable } \\
\text { - Useful }\end{array}$ & $\begin{array}{l}\text { 9. The designer can instill competition via leader boards. } \\
\text { 10. The designer can develop a more fun game to motivate the players to } \\
\text { continue learning the content. }\end{array}$ \\
\hline
\end{tabular}


Table 2 proposes the recommendation list based on our approach as guidelines for gamification designers to adapt for designing and developing a UIG.

\section{Discussion}

We analyzed the benefits of our approach in the healthcare domain and found the following results:

- Increased usability; for example, if the gamification designer considers the seven UX factors, the usability of the output would be drastically improved

- Increased level of awareness; for example, when the designer considers the treatment through gamification, the designer will support patients via the use of social technology treatment

- Improved level of attention; for example, if the patient has diabetes, he or she will receive indirect information about this disease by engaging in the gamification

\section{Conclusion}

Integrating gamification in the context of healthcare is essential; thus, each software engineer needs to understand the characteristics of the UX factors in gamification in terms of designing and developing mobile health games. We have introduced a new approach for mapping GM to UX factors and TTM stages in the healthcare domain. The mapping approach can enhance the acceptability of the technology in this domain, in which diversity is inherent.

For our future work direction, we plan to conduct additional research to determine the game design and behavior changes to enhance the effectiveness of gamification and reduce possible negative or adverse effects. We will experiment with applying our propose guidelines in designing gamification to improve the behavior of children with the habit of eating unhealthy food. Also, we will investigate the UX metrics in gamification regarding whether they are observable in some way, either directly or indirectly.

\section{Acknowledgment}

I would like to express my appreciation to my advisor, Dr. Reem Alnanih, who guided me through this research project.

\section{Author's Contributions}

All authors equally contributed in this work.

\section{Ethics}

This research article is original and has not been published elsewhere. The authors confirm that there are no ethical issues involved.

\section{References}

Brick, L.A.D., W.F. Velicer, C.A. Redding, J.S. Rossi and J.O. Prochaska, 2016. Extending theory-based quantitative predictions to new health behaviors. Int. J. Behav. Med., 23: 123-134. DOI: $10.1007 / \mathrm{s} 12529-015-9506-\mathrm{y}$

Briones, A.G., P. Chamoso, A. Rivas, S. Rodríguez and F. De La Prieta et al., 2018. Use of gamification techniques to encourage garbage recycling. A smart city approach. Proceedings of the 3rd International Conference on Knowledge Management in Organizations, Aug. 6-10, Žilina, Slovakia, pp: 674-685. DOI: $10.1007 / 978-3-319-95204-856$

Brondino, M., G. Dodero, R. Gennari, A. Melonio and D. Raccanello et al., 2014. Achievement emotions and peer acceptance get together in game design at school. Adv. Distributed Comput. Artificial Intell. J., 3: 1-12. DOI: 10.14201/ADCAIJ201434112

Bruder, P., 2015. GAME ON: Gamification in the classroom. Ann. Arbor., 80: 56-60.

Brull, S. and S. Finlayson, 2016. Importance of gamification in increasing learning. J. Continu. Educ. Nurs., 47: 372-375. DOI: $10.3928 / 00220124-20160715-09$

Cafazzo, J.A., M. Casselman, N. Hamming, D.K. Katzman and M.R. Palmert, 2012. Design of an mHealth app for the self-management of adolescent type 1 diabetes: A pilot study. J. Med. Internet Res., 14: e70-e70. DOI: 10.2196/jmir.2058

Cohen, A.M., 2011. The gamification of education. Futurist, 45: 16-17.

Connelly, K.H., A.M. Faber, Y. Rogers, K.A. Siek and T.J. Toscos et al., 2006. Mobile applications that empower people to monitor their personal health. Elektrotechnik Informationstechnik, 123: 124-128. DOI: $10.1007 / \mathrm{s} 00502-006-0326$

Dennison, L., L. Morrison, G. Conway and L. Yardley, 2013. Opportunities and challenges for smartphone applications in supporting health behavior change: Qualitative study. J. Med. Internet Res., 15: e86-e86. DOI: $10.2196 /$ jmir.2583

Deterding, S., D. Dixon, R. Khaled and L. Nacke, 2011. From game design elements to gamefulness: defining "gamification". Proceedings of the 15th International Academic MindTrek Conference: Envisioning Future Media Environments, Sept. 28-30, ACM, Tampere, Finland, pp: 9-15. DOI: $10.1145 / 2181037.2181040$

Donker, T., K. Petrie, J. Proudfoot, J. Clarke and M.R. Birch et al., 2013. Smartphones for smarter delivery of mental health programs: a systematic review. J. Med. Internet Res., 15: e247- e247. DOI: $10.2196 /$ jmir.2791 
Edwards, E.A., J. Lumsden, C. Rivas, L. Steed and L. Edwards et al., 2016. Gamification for health promotion: Systematic review of behaviour change techniques in smartphone apps. BMJ Open, 6: e012447-e012447.

DOI: 10.1136/bmjopen-2016-012447

Fanfarelli, J.R., R. McDaniel and C. Crossley, 2018. Adapting UX to the design of healthcare games and applications. Entertainment Comput., 28: 21-31. DOI: $10.1016 /$ j.entcom.2018.08.001

Ferguson, B., 2012. Games for wellness-impacting the lives of employees and the profits of employers. Games Health J. DOI: 10.1089/g4h.2012.0023

Ferrara, J., 2013. Games for persuasion: Argumentation, procedurality and the lie of gamification. Games Culture, 8: 289-304. DOI: $10.1177 / 1555412013496891$

Free, C., G. Phillips, L. Galli, L. Watson and L. Felix et al., 2013. The effectiveness of mobile-health technology-based health behaviour change or disease management interventions for health care consumers: A systematic review. PLOS, 10: e1001362-e1001362.

DOI: 10.1371/journal.pmed.1001362

González-Briones, A., P. Chamoso, S. Rodríguez, A. González-Arrieta and J.M. Corchado, 2018. Encouraging the recycling process of urban waste by means of game theory techniques using a multiagent architecture. Proceedings of the 16th IberoAmerican Conference on Artificial Intelligence, Nov. 13-16, Trujillo, Peru, pp: 120-131. DOI: $10.1007 / 978-3-030-03928-810$

Hamari, J., J. Koivisto and H. Sarsa, 2014. Does gamification work? -- A literature review of empirical studies on gamification. Proceedings of the 47th Hawaii International Conference on System Sciences, Jan. 6-9, IEEE Xplore Press, Waikoloa, HI, USA, pp: 3025-3034.

DOI: 10.1109/HICSS.2014.377

King, D., F. Greaves, C. Exeter and A. Darzi, 2013. Gamification': Influencing health behaviours with games. J. R Soc. Med., 106: 76-8. DOI: $10.1177 / 0141076813480996$

Lee, C., K. Lee and D. Lee, 2017. Mobile healthcare applications and gamification for sustained health maintenance. Sustainability, 9: 772-772. DOI: $10.3390 / \mathrm{su} 9050772$

Lister, C., J.H. West, B. Cannon, T. Sax and D. Brodegard, 2014. Just a fad? Gamification in health and fitness apps. JMIR Serious Games, 2: e9-e9. DOI: $10.2196 /$ games.3413
McGonigal, J., 2011. Reality is Broken: Why Games Make us Better and How they can Change the World. 1st Edn., Penguin, ISBN-10: 9780143120612 , pp: 416.

McGonigal, J., 2011. We spend 3 billion hours a week as a planet playing videogames. Is it worth it? How could it be MORE worth it?

Michie, S., M. Richardson, M. Johnston, C. Abraham and J. Francis et al., 2013. The behavior change technique taxonomy (v1) of 93 hierarchically clustered techniques: Building an international consensus for the reporting of behavior change interventions. Annals Behav. Med., 46: 81-95. DOI: $10.1007 / \mathrm{s} 12160-013-9486-6$

Payne, H.E., C. Lister, J.H. West, J. Bernhardt, M.J. Bernhardt, 2015. Behavioral functionality of mobile apps in health interventions: a systematic review of the literature. JMIR Mhealth Uhealth, 3: e20-e20. DOI: $10.2196 /$ mhealth.3335

Prakash, E.C. and M. Rao, 2015. Introduction to Gamification. In: Transforming Learning and IT Management through Gamification, Springer, Cham, pp: 35-46.

Prochaska, J.O., 2013. Transtheoretical Model of Behavior Change. In: Encyclopedia of Behavioral Medicine, Gellman, M.D. and J.R. Turner (Eds.), Springer, New York, pp: 1997-2000.

Savoia, E., L. Lin and K. Viswanath, 2013. Communications in public health emergency preparedness: A systematic review of the literature. Biosecurity Bioterrorism: Biodefense Strategy Pract. Sci., 11: 170-184. DOI: 10.1089/bsp.2013.0038

Sethares, K.A. and K. Elliott, 2004. The effect of a tailored message intervention on heart failure readmission rates, quality of life and benefit and barrier beliefs in persons with heart failure. Heart Lung, 33: 249-260.

DOI: $10.1016 /$ j.hrtlng.2004.03.005

Silva, F. and C. Analide, 2015. Tracking context-aware well-being through intelligent environments. Adv. Distr. Comput. Artificial Intell. J., 4: 61-72.

DOI: 10.14201/ADCAIJ2015426172

Sims, G., 2015. Google play store vs the apple app store: By the numbers.

Werbach, K. and D. Hunter, 2012. For the Win: How Game Thinking Can Revolutionize Your Business. 1st Edn., Wharton Digital Press, Philadelphia, ISBN-10: 1613630239, pp: 148. 